\title{
Kinetic Modeling of Nitration of Glycerol
}

\author{
Erna Astuti ${ }^{1,2}$, Supranto ${ }^{1}$, Rochmadi ${ }^{1}$, Agus Prasetya ${ }^{1}$, Krister Ström ${ }^{3} \&$ Bengt Andersson ${ }^{3}$ \\ ${ }^{1}$ Department of Chemical Engineering, Gadjah Mada University, Yogyakarta, Indonesia \\ ${ }^{2}$ Department of Chemical Engineering, Ahmad Dahlan University, Yogyakarta, Indonesia \\ ${ }^{3}$ Department of Chemical and Biological Engineering, Chalmers University of Technology, Göteborg, Sweden \\ Correspondence: Erna Astuti, Department of Chemical Chemical Engineering, Ahmad Dahlan University, Jl. \\ Prof. Dr. Soepomo, S. H., Janturan, Warungboto, Umbulharjo, Yogyakarta 55164, Indonesia. Tel: \\ 62-274-563-515. E-mail: erna.astuti@che.uad.ac.id
}

Received: October 8, 2013

doi:10.5539/mas.v8n2p78
Accepted: February 21, $2014 \quad$ Online Published: March 11, 2014

URL: http://dx.doi.org/10.5539/mas.v8n2p78

\begin{abstract}
Glycerol can be synthesized to make 1,3-dinitroglycerin as an intermediate product to produce polyglycidyl nitrate. This study performed kinetic modeling of nitration used elementary reactions that consisting of seven reversible reactions. The aim of this present work is to find out the representing reaction of seven reactions tested. The concept work is to study the reaction rates and its relation to the position of the nitrated hydroxyl group in the molecule. Nitration of glycerol to 1,3-dinitroglycerin was studied in the temperature range $10-30{ }^{\circ} \mathrm{C}$, the molar ratio of nitric acid to glycerol $1 / 1$ to $7 / 1$ and nitric acid concentration of $69 \%$. The seven reaction terms represent the reactions that occurred in the nitration of glycerol. The position of hydroxyl group in molecule causes difference reaction rate. The primary hydroxyl group is more reactive than secondary hydroxyl group. The parameter values describe that the $1^{\text {st }}, 3^{\text {rd }}, 5^{\text {th }}$ and $7^{\text {th }}$ reaction rates are very fast. On the contrary, the $2^{\text {nd }}, 4^{\text {th }}$ and $6^{\text {th }}$ reaction rates are slow.
\end{abstract}

Keywords: nitration, glycerol, kinetic modeling

\section{Introduction}

Polyglycidyl nitrate (PGN) is an energetic polymer that is used as a binder in propellant (Willer \& McGrath, 1997), plasticizer (Willer et al., 1995) and explosives (Braithwaite et al., 1996). PGN is the most energetic polymer (Provatas, 2000). Three steps in production of PGN from glycerol are nitration, cyclization and polymerization. Glycerol is by product of biodiesel industry that need purification before was used as reactant (Ayoub \& Abdullah, 2012; Kiss \& Ignat, 2012). The production of PGN is an alternative process to increase economic value of biodiesel industry. This paper focuses in nitration. Nitration produces 1-MNG (1-mononitroglycerin), 2-MNG (2-mononitroglycerin), 1,3-DNG (1,3-dinitroglycerin), 1,2-DNG (1,2-dinitroglycerin) and TNG (trinitroglycerin). It is necessary to study kinetics parameter of nitration. Basic knowledge of engineering is able to analyze and exploit fundamental reactions in production of PGN. The aim of this present work is to find out the representing reactions of nitration of glycerol. The reaction rate constants at average temperature and the activation energies will be fitted.

There have been several studies related to the nitration of glycerol. Nitration equilibrium in glycerol-aqueous system has been known (Kazakov et al., 1990a, 1990b; Yunda et al., 1991). Highsmith et al. (2002), Sanderson \& Martins (2004), and Sanderson et al. (2005) proposed several examples of synthesizing glycidyl nitrate from glycerol. Then Highsmith and Johnston (2005) invented the continuous process production of glycidyl nitrate from glycerol with 1,3 dinitroglycerine as intermediate products. The kinetics parameter of nitroglycerin in the CSTR of Biazzi Process was presented by $\mathrm{Lu}$ et al. (2008). The temperature effect on glycerol nitration was studied by Astuti et al. (2014). Nitration of glycerol and nitric acid is a combination of both consecutive and parallel reactions (see Table 1): 
Table 1. Nitration reactions

\begin{tabular}{|c|c|c|c|}
\hline Reaction number & & Reaction & $\Delta \mathrm{H}_{\mathrm{R}}, \mathrm{kJ} / \mathrm{mole}$ \\
\hline 1 & $\mathrm{G}+\mathrm{HNO}_{3}$ & $\leftrightarrow 1 \mathrm{MNG}+\mathrm{H}_{2} \mathrm{O}$ & -59.4 \\
\hline 2 & $\mathrm{G}+\mathrm{HNO}_{3}$ & $\leftrightarrow 2 \mathrm{MNG}+\mathrm{H}_{2} \mathrm{O}$ & -50.6 \\
\hline 3 & $1 \mathrm{MNG}+\mathrm{HNO}_{3}$ & $\leftrightarrow 1,3 \mathrm{DNG}+\mathrm{H}_{2} \mathrm{O}$ & -51.5 \\
\hline 4 & $1 \mathrm{MNG}+\mathrm{HNO}_{3}$ & $\leftrightarrow 1,2 \mathrm{DNG}+\mathrm{H}_{2} \mathrm{O}$ & -46.4 \\
\hline 5 & $2 \mathrm{MNG}+\mathrm{HNO}_{3}$ & $\leftrightarrow 1,2 \mathrm{DNG}+\mathrm{H}_{2} \mathrm{O}$ & -55.6 \\
\hline 6 & $1,3 \mathrm{DNG}+\mathrm{HNO}_{3}$ & $\leftrightarrow \mathrm{TNG}+\mathrm{H}_{2} \mathrm{O}$ & -44.4 \\
\hline 7 & $1,2 \mathrm{DNG}+\mathrm{HNO}_{3}$ & $\leftrightarrow \mathrm{TNG}+\mathrm{H}_{2} \mathrm{O}$ & -49.4 \\
\hline
\end{tabular}

Source: Astuti et al., 2014.

These previous studies also described the temperature dependences of equilibrium constants of all the reactions above and the corresponding values of Gibb's energies, enthalpy, and entropy $(\Delta \mathrm{G}, \Delta \mathrm{H}, \Delta \mathrm{S})$ were obtained (Kazakov et al., 1990b). Rubstov and Kazakov (1997) stated that the equilibrium constants of nitration to the hydroxyl group at the secondary carbon atoms are 3 to 10 times are lower than equilibrium constants for the primary hydroxyl groups in the single-type compounds.

Order reaction is needed to arrange reaction rate equation. Nitrations of some compounds have successfully been modeled as first order with respect to each reactant. The nitration of benzene and some more reactive compounds in sulphuric acid (Coombes et al., 1968), nitration of benzene, chlorobenzene, toluene, and the di- and trimethylbenzenes in trifluoroacetic acid (Moodie et al., 1977) and nitration of the same reactant in perchloric acid (Moodie et al., 1978) are the first order reaction with respect to each other. The oxidation of 2-octanol with nitric acid is also first order with respect to 2-octanol and nitric acid (Van Woezik \& Westerterp, 2000). The reaction rate of trinitroglycerin formation from glycerol and nitric acid in the CSTR of Biazzi process can be expressed as (Lu et al., 2008):

$$
-r_{G}=k C^{n}{ }_{G} C_{N}^{m}=A e^{-E / R T} C^{n}{ }_{G} C^{m}
$$

The values of $\mathrm{n}$ and $\mathrm{m}$ have been determined to be 0.9350 and 1.117 (Lu et al., 2008).

This present work decribes kinetic modeling of glycerol nitration. The kinetics parameter which was calculated is rate constants for all reaction that happened in glycerol nitration at average temperature and activation energy. This paper also describes the relationship between the position of hydroxyl group and reaction rate.

\section{Method}

\subsection{Kinetics Model Development}

Referring to previous studies, in this work the obtained experimental data were treated on the hypothesis that the rate of glycerol nitration was described by first order with respect to each reactant. For many reactions involving multiple steps and pathways, the powers in the rate laws agree with the stoichiometric coefficients indicating a simple kinetic mechanism. Based on the nitration reaction (Table 1), the equation rates of nitration are defined as:

$$
\begin{gathered}
-\frac{d C_{G}}{d t}=k_{1} C_{G} C_{H N O 3}+k_{2} C_{G} C_{H N O 3}-k_{-1} C_{1 M N G} C_{H 2 O}-k_{-2} C_{2 M N G} C_{H 2 O} \\
-\frac{d C_{1 M N G}}{d t}=k_{-1} C_{1 M N G} C_{H 2 O}+k_{3} C_{1 M N G} C_{H N O 3}+k_{4} C_{1 M N G} C_{H N O 3}-k_{1} C_{G} C_{H N O 3}- \\
k_{-3} C_{1,3 D N G} C_{H 2 O}-k_{-4} C_{1,2 D N G} C_{H 2 O} \\
-\frac{d C_{2 M N G}}{d t}=k_{-2} C_{2 M N G} C_{H 2 O}+k_{5} C_{2 M N G} C_{H N O 3}-k_{2} C_{G} C_{H N O 3}-k_{-5} C_{1,2 D N G} C_{H 2 O} \\
-\frac{d C_{1,3 D N G}}{d t}=k_{-3} C_{1,3 D N G} C_{H 2 O}+k_{6} C_{1,3 D N G} C_{H N O 3}-k_{3} C_{1 M N G} C_{H N O 3}-k_{-6} C_{N G} C_{H 2 O} \\
-\frac{d C_{1,2 D N G}}{d t}=k_{-4} C_{1,2 D N G} C_{H 2 O}+k_{-5} C_{1,2 D N G} C_{H 2 O}+k_{7} C_{1,2 D N G} C_{H N O 3}-k_{4} C_{1 M N G} C_{H N O 3} \\
-k_{5} C_{2 M N G} C_{H N O 3} \\
-\frac{d C_{N G}}{d t}=k_{-6} C_{N G} C_{H 2 O}-k_{6} C_{1,3 D N G} C_{H N O 3}-k_{7} C_{1,2 D N G} C_{H N O 3}
\end{gathered}
$$




$$
\begin{gathered}
-\frac{d C_{H N O 3}}{d t}=k_{1} C_{G} C_{H N O 3}+k_{2} C_{G} C_{H N O 3}+k_{3} C_{1 M N G} C_{H N O 3}+k_{4} C_{1 M N G} C_{H N O 3}+k_{5} C_{2 M N G} C_{H N O 3} \\
+k_{6} C_{1,3 D N G} C_{H N O 3}+k_{7} C_{1,2 D N G} C_{H N O 3}-k_{-1} C_{1 M N G} C_{H 2 O}-k_{-2} C_{2 M N G} C_{H 2 O}-k_{-3} C_{1,3 D N G} C_{H 2 O}- \\
k_{-4} C_{1,2 D N G} C_{H 2 O}-k_{-5} C_{1,2 D N G} C_{H 2 O}-k_{-6} C_{N G} C_{H 2 O} \\
-\frac{d C_{H 2 O}}{d t}=-k_{1} C_{G} C_{H N O 3}-k_{2} C_{G} C_{H N O 3}-k_{3} C_{1 M N G} C_{H N O 3}-k_{4} C_{1 M N G} C_{H N O 3}-k_{5} C_{2 M N G} C_{H N O 3}- \\
k_{6} C_{1,3 D N G} C_{H N O 3}-k_{7} C_{1,2 D N G} C_{H N O 3}+k_{-1} C_{1 M N G} C_{H 2 O}+k_{-2} C_{2 M N G} C_{H 2 O}+k_{-3} C_{1,3 D N G} C_{H 2 O}+ \\
k_{-4} C_{1,2 D N G} C_{H 2 O}+k_{-5} C_{1,2 D N G} C_{H 2 O}+k_{-6} C_{N G} C_{H 2 O}
\end{gathered}
$$

The kinetics parameter can be evaluated using the experimental data. The rate constant, $\mathrm{k}_{\mathrm{ref}, \mathrm{i}}$, at an average temperature $\left(T_{\text {ref }}\right.$ of $293.15 \mathrm{~K}$ ) and the activation energy, $E_{A}$ were fitted. The backward reactions for each reaction were calculated using the equilibrium constant obtained from experimental data. The Arrhenius equation for the forward and backward reactions is:

$$
k_{i}=k_{r e f, i} e^{\frac{E_{A i}}{R}\left(\frac{1}{T_{r e f}}-\frac{1}{T}\right)} \text { and } \quad k_{-i}=k_{i} / K_{i}
$$

The parameter were fitted by minimizing was the residual sums of squares of errors (SSE) for the measured concentrations of glycerol, 1-MNG, 2-MNG, 1,3-DNG, 1,2-DNG and TNG. Since steady reaction conditions were not reached immediately the first measured data point was used as a starting value when solving the differential equations describing the reactions. However, this value is also prune to measurement errors and parameters $P_{i}$ was introduced to estimate the true initial condition. A least squares minimization with respect to these parameters was also introduced.

SSE is defined as:

$$
S S E=\sum \frac{\left(Y_{\text {calc }, i}-Y_{\text {dat }, i}\right)^{2}}{\left(\text { MeanY }_{\text {dat }, i}\right)^{2}}+\sum \frac{\left(P_{i}-Y_{\text {init }, i}\right)^{2}}{\left(\text { MeanY }_{\text {dat }, i}\right)^{2}}
$$

The weight factor $\left(\text { Mean } Y_{\text {dat }, i}\right)^{2}$ is to normalize the residual sum of squares assuming constant relative error in the concentration measurements. The function lsqnonlin with solver ode 15s in MATLAB 7.6 was used to obtain $\mathrm{k}_{\mathrm{ref}, \mathrm{i}}$ and $\mathrm{E}_{\mathrm{A}, \mathrm{i}}$.

\subsection{Experimental Set up}

The reactants used in the experiments were glycerol of $\geq 99 \%$ purity from Sigma-Aldrich, nitric acid of $69 \%$ purity from Merck and 1,2-dichloroethane of purity $\geq 99.0 \%$ from Sigma-Aldrich. Experiments were carried out in a $5 \mathrm{~cm}^{3}$ flask that was immersed in cooling bath. Glycerol with a certain weight was placed in flask and was diluted with an equal volume of dichloroethane and cooled to reaction temperature. Cooled nitric acid was added. The flask equipped with nitrogen purge for stirring. A thermometer monitored the temperature in the flask. Samples were taken in time intervals between 45-60 minutes, 10 samples in each experiment. Furthermore the reactions were continued until equilibrium conditions and the sample was taken. Experimental works were done with various variables i.e. reaction temperature $\left(10\right.$ to $\left.30^{\circ} \mathrm{C}\right)$ and molar ratio $(1 / 1$ to $7 / 1)$.

\subsection{Analytical Methods}

Samples were analyzed with gas chromatography (430 GC, Bruker), equipped with flame ionization detector. The column was a VF-1 ms $30 \mathrm{~m} \times 0.25 \mathrm{~mm}$, ID DF=1 capillary column from Factor Four. The injector and detector temperature were maintained at 175 and $225 \mathrm{C}$, respectively. The oven temperature was kept at $60{ }^{\circ} \mathrm{C}$ during injection, after that increase to $140{ }^{\circ} \mathrm{C}$ and stabile at that temperature. Chromatogram were recorded by computer that used Galaxie Chromatography System version 1.9.302.952 and gave the percent mass of 1-MNG, 2-MNG, 1,3-DNG, 1,2-DNG, TNG and glycerol of each samples, respectively.

A sampling procedure was developed to minimize the time between sampling and GC analysis and to be as reproducible as possible. Still the measured concentrations show large scattering. 


\section{Results and Discussion}

\subsection{Equilibrium Constants}

This paper compares the equilibrium constants which were proposed by Kazakov et al. (1990a) and equilibrium constants from experimental work. The aim of this comparison was to choose equilibrium constants that were used in simulation. The comparison can be read at Table 2 .

Table 2. Equilibrium constants from Kazakov et al. (1990a) and from experimental works

\begin{tabular}{ccccccccc}
\hline \multirow{2}{*}{ Molar ratio } & $\begin{array}{c}\text { Temperature, } \\
{ }^{\circ} \mathrm{C}\end{array}$ & $\mathrm{K}_{1}$ & $\mathrm{~K}_{2}$ & $\mathrm{~K}_{3}$ & $\mathrm{~K}_{4}$ & $\mathrm{~K}_{5}$ & $\mathrm{~K}_{6}$ & $\mathrm{~K}_{7}$ \\
\hline Kazakov's & 10 & 0.0026 & 1.3890 & 7.6074 & 2.0646 & 11.1655 & 0.4672 & 1.7210 \\
& 15 & 0.0026 & 1.2801 & 8.7083 & 2.4572 & 12.5396 & 0.4401 & 1.5590 \\
& 20 & 0.0026 & 1.1831 & 9.9226 & 2.9071 & 14.0271 & 0.4155 & 1.4171 \\
& 30 & 0.0026 & 1.0184 & 12.7176 & 4.0020 & 17.3587 & 0.3723 & 1.1819 \\
\hline $1 / 1$ & 10 & 0.0106 & 0.0365 & 6.1397 & 0.6715 & 9.4015 & 0.2906 & 2.6565 \\
& 15 & 0.0053 & 0.0304 & 10.1324 & 1.1013 & 2.2027 & 0.2448 & 2.2521 \\
& 20 & 0.0056 & 0.0361 & 11.3405 & 1.1674 & 4.6056 & 0.2717 & 2.6389 \\
& 30 & 0.0078 & 0.0329 & 7.4198 & 0.6625 & 1.1041 & 0.1512 & 1.6934 \\
\hline $3 / 1$ & 10 & 0.1351 & 0.1539 & 2.0818 & 0.1376 & 5.5055 & 0.4604 & 6.9630 \\
& 15 & 0.1639 & 0.2231 & 2.6187 & 0.2414 & 6.2775 & 0.4705 & 5.1034 \\
& 20 & 0.0760 & 0.3489 & 8.8792 & 0.6107 & 18.9329 & 0.0574 & 0.8352 \\
& 30 & 0.1129 & 0.6849 & 13.7496 & 0.9228 & 17.0716 & 0.3173 & 4.7273 \\
\hline $5 / 1$ & 10 & 0.3177 & 0.4347 & 2.6020 & 0.1694 & 15.7508 & 0.4692 & 7.2092 \\
& 15 & 0.4736 & 0.6918 & 2.9312 & 0.1937 & 22.6619 & 0.4111 & 6.2217 \\
& 20 & 0.1953 & 1.0903 & 11.4168 & 0.4779 & 1.5399 & 0.0839 & 2.0046 \\
& 30 & 0.5858 & 1.5508 & 5.8457 & 0.2682 & 4.1564 & 0.1949 & 4.2496 \\
\hline $7 / 1$ & 10 & 0.8956 & 1.4346 & 3.3170 & 0.1824 & 17.1486 & 0.7970 & 14.4904 \\
& 15 & 0.4690 & 0.8694 & 3.5345 & 0.1698 & 5.2632 & 0.3672 & 7.6439 \\
& 20 & 1.0209 & 1.5996 & 3.1964 & 0.1799 & 1.5359 & 0.6019 & 10.6957 \\
& 30 & 2.3883 & 4.0404 & 3.8210 & 0.1800 & 15.3039 & 0.5689 & 12.0735 \\
\hline & & & & & & & &
\end{tabular}

Table 2 shows that Kazakov's constants do not fit properly. Equilibrium constants vary with the molar ratio. Hence, Kasakov's constants were replaced by the equilibrium contants obtained from experiments for estimation of kinetics parameter.

Experimental data have been measured in the nitration of glycerol. The nitration between glycerol and nitric acid was modeled by fitting the kinetic model with 14 parameters, $\mathrm{k}_{\mathrm{ref}, 1}$ to $\mathrm{k}_{\mathrm{ref}, 7}$ and $\mathrm{E}_{\mathrm{A}, 1}$ to $\mathrm{E}_{\mathrm{A}, 7}$ to the experimental data. Figure 1 shows the comparison between the experimental data measured and calculated data points of the six compounds that are involved in nitration. Concentrations were plotted as a function of time. 


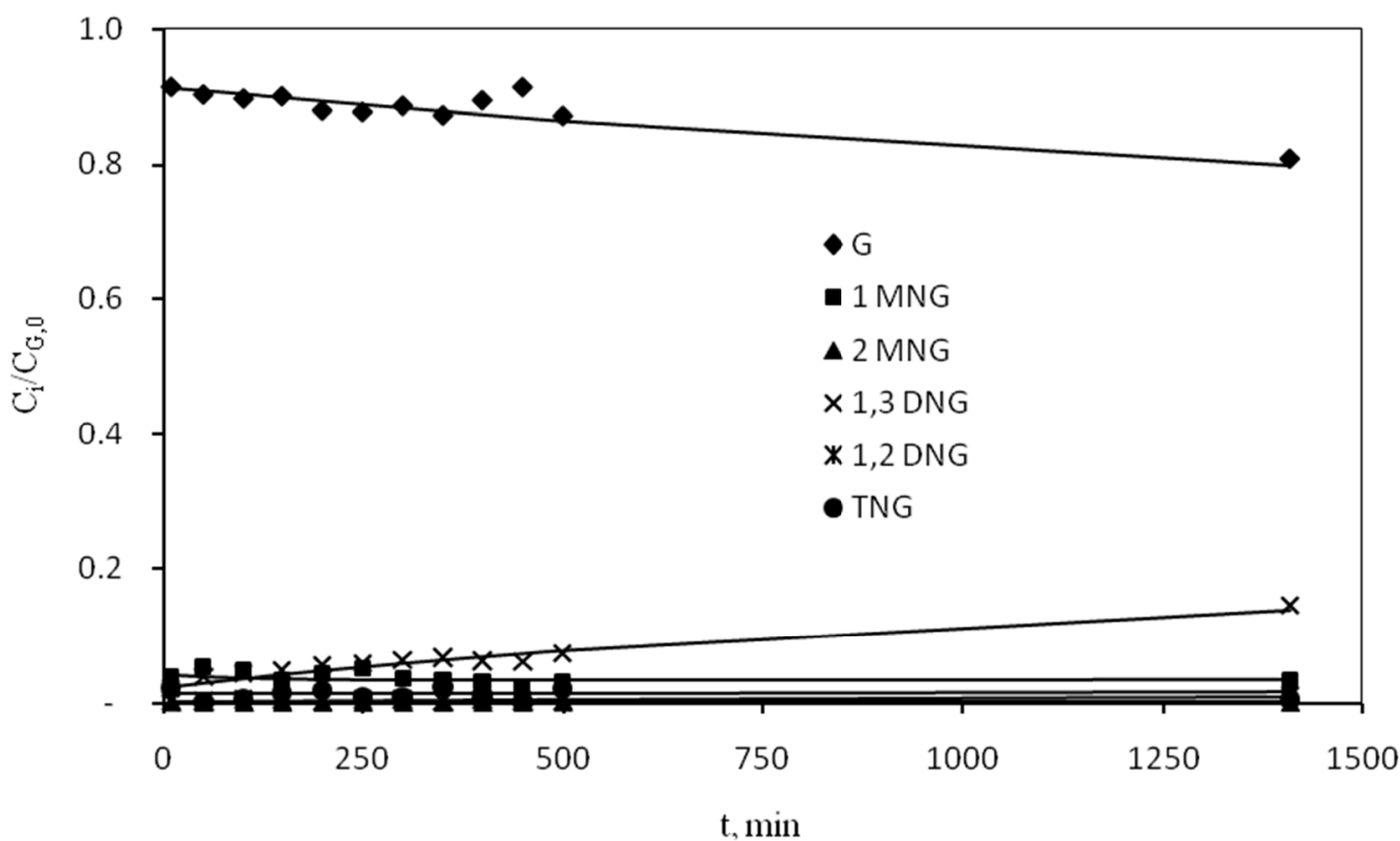

Figure 1. $\mathrm{C}_{\mathrm{i}} / \mathrm{C}_{\mathrm{G}, 0}$ of all products for nitration of glycerol at nitric acid of $69 \%$, molar ratio of nitric acid/glycerol $3 / 1$ and temperature of reaction $20^{\circ} \mathrm{C}$

The nitration of glycerol produces five different compounds: two isomers of mononitroglycerin (1-MNG and 2-MNG), two isomers of dinitroglycerin (1,3-DNG and 1,2-DNG) and trinitroglycerin (TNG). Figure 1 shows that largest $\mathrm{C}_{\mathrm{i}} / \mathrm{C}_{\mathrm{G}, 0}$ is the $\mathrm{C}_{\mathrm{i}} / \mathrm{C}_{\mathrm{G}, 0}$ of 1,3-DNG. It is advantageous because 1,3-DNG is the main product expected from this nitration. Concentration of 2-MNG and 1,2-DNG are very small, nearest to zero. Equilibrium is reached at the beginning of the reaction. This case will be evaluated based on the estimated value of the parameter obtained from the calculation.

\subsection{Influence of Temperature}

Rate of reaction usually increases nearly exponentially as temperature increases. The synthesize of 1,3-DNG is an endhotermic reaction (Kazakov et al., 1990b). If the reaction is endothermic ( $\Delta \mathrm{H}^{\circ}$ positive) the equilibrium constant increases with temperature.

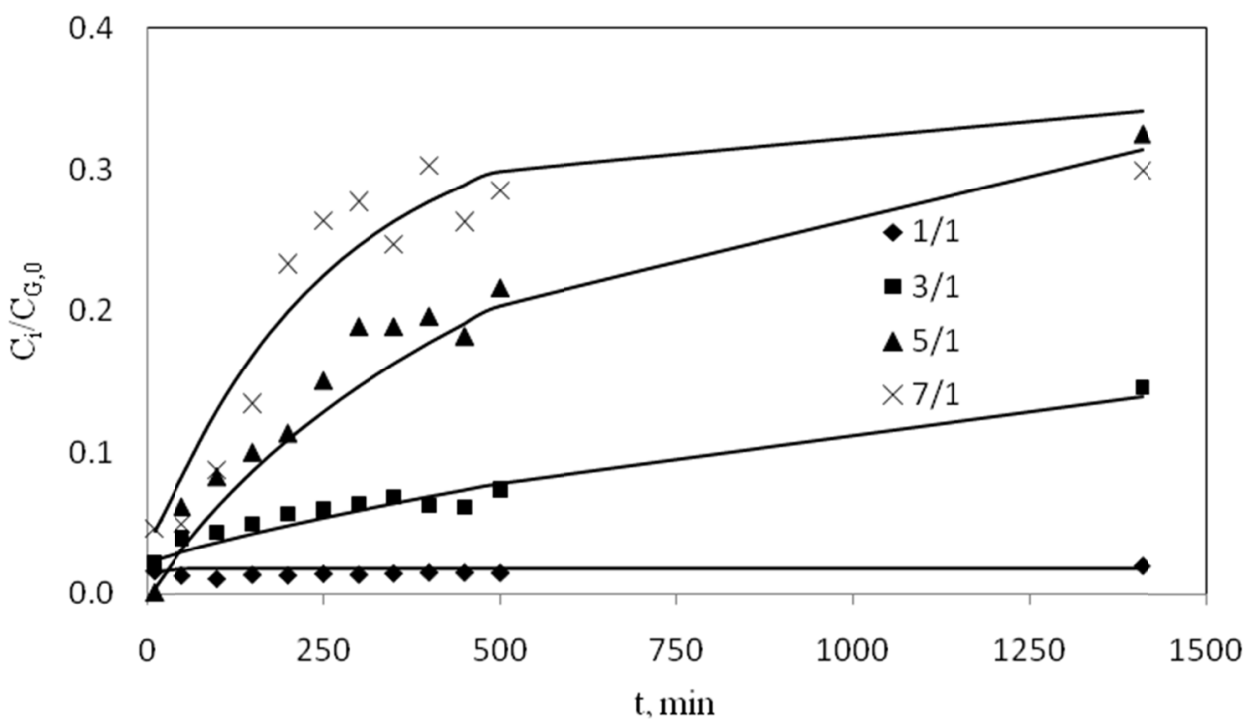

Figure 2. $\mathrm{C}_{\mathrm{i}} / \mathrm{C}_{\mathrm{G}, 0}$ of 1,3-DNG at difference temperatures ( nitric acid of $69 \%$, molar ratio of 3/1) 
It can be seen in Figure 2 that higher reaction temperature cause significant increase in the conversion of 1,3-DNG. An increase in temperature has tendency to increase the reaction rate by diminishing the resistance factor. The restriction of reaction temperature in nitration is the decomposition of trinitroglycerin that occurred at temperature above $20{ }^{\circ} \mathrm{C}$ which is dangerous for safety. The kinetic model was able to describe well the time dependence of all measured concentration especially $1,3-\mathrm{DNG}$ in the low temperature $\left(10-20^{\circ} \mathrm{C}\right)$.

\subsection{Influence of Molar Ratio}

Experiments were carried out at molar ratio of nitric acid to glycerol $1 / 1$ to $7 / 1$. The kinetics parameter was determined separately at each molar ratio of nitric acid/glycerol. Increase in mole ratio will increase the concentration of nitric acid in the system so that the equilibrium reaction will shift to the right. Increasing mole ratio, as seen in Figure 3, clearly increased the $\mathrm{C}_{\mathrm{i}} / \mathrm{C}_{\mathrm{G}, 0}$ of 1.3-DNG. The model is very appropriate at molar ratio $1 / 1$ to $5 / 1$.

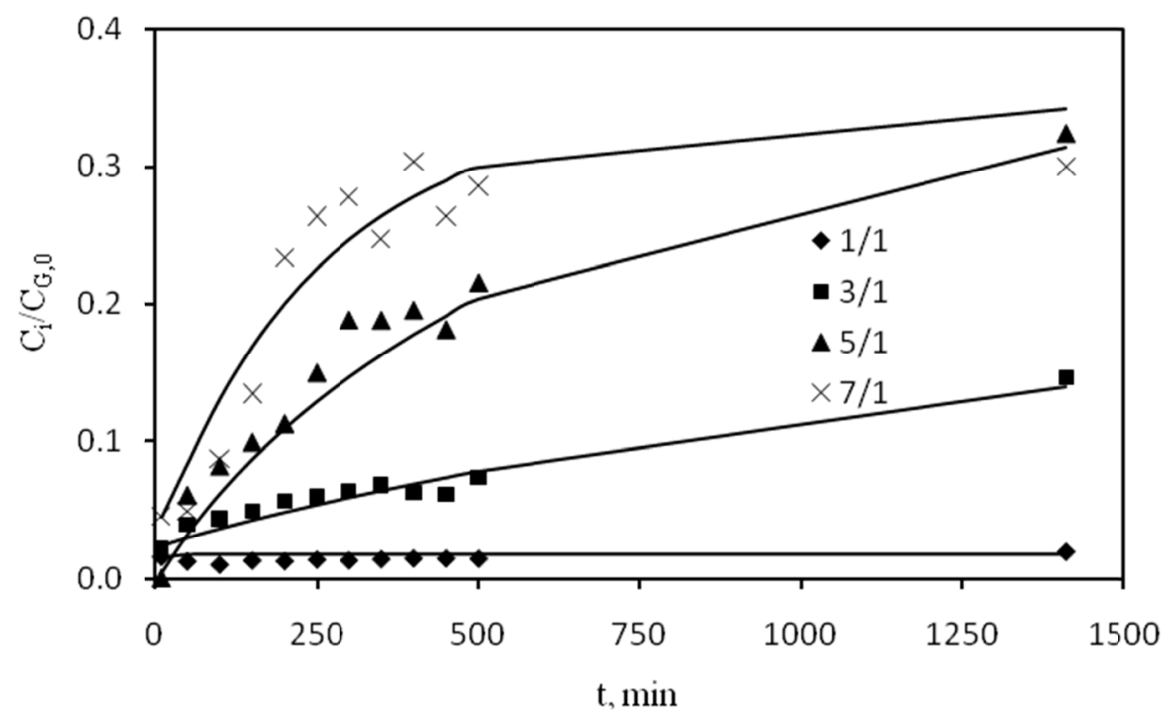

Figure 3. Experimental and estimated $\mathrm{C}_{\mathrm{i}} / \mathrm{C}_{\mathrm{G}, 0}$ of $1,3-\mathrm{DNG}$ at various mole ratio of nitric acid/glycerol (nitric acid of $69 \%$, temperature of $20^{\circ} \mathrm{C}$ )

This research also studied the effect of the molar ratio and the reaction temperature to yield 1.3-DNG. Increase in molar ratio of nitric acid/glycerol means increase in concentration of nitric acid. Figure 3 and Table 2 show the influence of mole ratio upon the yield of the products.

Table 3. Maximum yield of 1,3-DNG

\begin{tabular}{cccccc}
\hline Molar ratio & $\begin{array}{c}\text { Temperature, } \\
{ }^{\circ} \mathrm{C}\end{array}$ & $\begin{array}{c}\text { Maximum } \\
\text { yield, } \%\end{array}$ & Molar ratio & $\begin{array}{c}\text { Temperature, } \\
{ }^{\circ} \mathrm{C}\end{array}$ & $\begin{array}{c}\text { Maximum } \\
\text { yield, \% }\end{array}$ \\
\hline $1 / 1$ & 10 & 1.64 & $5 / 1$ & 10 & 1.57 \\
& 15 & 5.13 & & 15 & 8.28 \\
& 20 & 11.05 & & 20 & 22.26 \\
$3 / 1$ & 30 & 22.93 & & 30 & 28.57 \\
& 10 & 1.53 & $7 / 1$ & 10 & 1.68 \\
& 15 & 6.15 & & 15 & 13.42 \\
& 20 & 15.14 & & 20 & 32.94 \\
& 30 & 25.09 & & 30 & 38.70 \\
\hline
\end{tabular}

As seen in Table 3, increase in molar ratio will increase the yield of 1,3-DNG. This fact supports the theory of the dependence of reaction rate on the concentration of the compounds present. At the highest molar ratio (7/1), 
the deviation between the experimental yield and the yield of simulation is rather large. To some extent this is due to the high reaction rate at high concentrations of nitric acid and further reaction occurred prior to GC analysis. The same reason reliable to explain the deviation at highest reaction temperature $303.15 \mathrm{~K}$.

\subsection{Parameter Estimation}

The resulting parameter values and their $95 \%$ confidence intervals are shown in Table 4 . The sum of all nitro compounds excluding 1-MNG and 1,3-DNG was always less than $10 \%$ of all nitro compounds. Parameter estimation gave the result with arbitrary values for some reactions. Low concentration of 2-MNG and 1,2-DNG lead the accuracy were very low. As a consequence, confidence interval for the $2^{\text {st }}, 4^{\text {rd }}$, and $6^{\text {th }}$ reactions are very low. The estimation parameters (see Table 4) showed the difference between rates of nitration at the primary and secondary hydroxyl groups. The primary hydroxyl group is more reactive than secondary hydroxyl group. Reaction that fill nitrate group at first carbon atom and third carbon atom is faster than at secondary carbon atom. The $1^{\text {st }}, 3^{\text {rd }}, 5^{\text {th }}$ and $7^{\text {th }}$ reactions are the nitration of primary hydroxyl group so the reactions are fast relatively to the others. The reaction rate constants are high. Otherwise the $2^{\text {nd }}, 4^{\text {th }}$ and $6^{\text {th }}$ reactions related the existence of secondary hydroxyl groups. The reaction rates are slow and the reaction rates constants are low too. This phenomenon is in line with Kazakov et al. (1990b) and Rubstov and Kazakov (1997). Kazakov et al. stated (1990b) that heat of reaction for the reaction of substitution of a primary hydroxyl is greater than for the reactions of substitution of a secondary hydroxyl. According to Rubstov et al. (1997), in polyhydric alcohols the existence of the nitrate group at the primary carbon atom increases equilibrium constants for the nitration of the secondary hydroxyl group.

It can be seen in Figure 1 the concentrations of $2-\mathrm{MNG}$ and $1,2-\mathrm{DNG}$ are very low. The $2^{\text {nd }}$ reaction rate that including secondary hydroxyl group is very slow that causes the concentration of 2-MNG as product is very low. There are three reasons for the low concentration of 1,2-DNG. First, at the $4^{\text {th }}$ reaction the active functional group is a secondary nitrate group. Therefore the formation of 1,2-DNG from 1-MNG was very slow. Second, the reaction rate of $5^{\text {th }}$ reaction (the formation of 1,2-DNG from 2-MNG) is fast but the concentration of 2-MNG is very small so the concentration of $1,2-\mathrm{DNG}$ as product is also very small. Third, the reaction rate of $7^{\text {th }}$ reaction (the formation of TNG from 1,2-DNG) is fast. The 1,2-DNG disappear very quickly and turn to TNG.

A different experimental design with different initial compositions including some of the products would be necessary in order to obtain significant parameters for the remaining reactions. However, that was not the objective of this study. Representing reactions for the nitration reaction are known.

Table 4. Kinetic parameters for nitration of glycerol (nitric acid concentration 0f 69\%, 293.15K)

\begin{tabular}{llllll}
\hline $\begin{array}{l}\text { Reaction } \\
\text { number }\end{array}$ & \multicolumn{5}{c}{$\mathrm{k}_{\text {ref }}, \mathrm{m}^{3} / \mathrm{mol}, \mathrm{s} .10^{10}$} \\
\hline & $1 / 1$ & $3 / 1$ & $5 / 1$ & $7 / 1$ & all \\
\hline 1 & $1034134.55 \pm 65373133.83$ & $5.77 \pm 0.34$ & $15.24 \pm 0.64$ & $235.38 \pm 19.03$ & $0.5 \pm 0.15$ \\
2 & $0.02 \pm 0.20$ & $0.05 \pm 0.10$ & $1.59 \pm 0.30$ & $4.17 \pm 1.32$ & $0.49 \pm 0.14$ \\
3 & $86632.50 \pm 313434.38$ & $80.18 \pm 3.22$ & $117.22 \pm 5.72$ & $89.97 \pm 1.21$ & $97.79 \pm 7.82$ \\
4 & $3805.42 \pm 8375.65$ & $2.33 \pm 3.65$ & $4.90 \pm 6.89$ & $34.60 \pm 8.38$ & $26.17 \pm 10.42$ \\
5 & $3.72 \pm 156.23$ & $59.91 \pm 110.02$ & $10803.65 \pm 150411.43$ & $246130.55 \pm 13263348.16$ & $1319.12 \pm 1727.00$ \\
6 & $56.82 \pm 13.45$ & $0.94 \pm 0.72$ & $2.28 \pm 0.39$ & $1.58 \pm 0.06$ & $30.77 \pm 3.11$ \\
7 & $857.40 \pm 282.03$ & $2.44 \pm 7.34$ & $103.54 \pm 33.07$ & $716.19 \pm 69.27$ & $194.64 \pm 34.00$ \\
\hline & & & Activation energy, kJ/mol & $38.11 \pm 13.89$ \\
\hline 1 & $38.10 \pm 3692.52$ & $38.10 \pm 4.21$ & $38.15 \pm 2.56$ & $38.12 \pm 5.52$ & $117.23 \pm 12.44$ \\
2 & $117.23 \pm 1441.48$ & $117.23 \pm 105.65$ & $117.23 \pm 11.62$ & $117.23 \pm 2.57$ & $58.62 \pm 6.68$ \\
3 & $58.62 \pm 332.69$ & $58.62 \pm 3.40$ & $58.69 \pm 3.97$ & $58.64 \pm 1.20$ & $31.40 \pm 21.67$ \\
4 & $31.40 \pm 129.65$ & $31.40 \pm 67.81$ & $31.40 \pm 79.80$ & $31.38 \pm 12.44$ & $167.48 \pm 95.45$ \\
5 & $167.47 \pm 3061.09$ & $167.48 \pm 147.73$ & $167.48 \pm 406.37$ & $167.46 \pm 880.47$ & $104.53 \pm 10.07$ \\
6 & $104.67 \pm 32.10$ & $104.53 \pm 50.04$ & $104.51 \pm 14.36$ & $104.53 \pm 2.97$ & $71.89 \pm 14.92$ \\
\hline 7 & $71.18 \pm 31.58$ & $71.89 \pm 192.41$ & $71.90 \pm 24.04$ & $71.84 \pm 6.61$ & \\
\hline
\end{tabular}


The model satisfactory captures the reactions of nitration as seen in Figures 1-3. The model gives good results at low temperature and low molar ratio. Model accuracy was not impaired by merging of the data sets obtained at four molar ratios (the result is symbolized by all in Table 4). The parameter values obtained for the merge data set is in the range of the parameter values which determined separately. The results obtained show the influence of composition of reactants on the reaction rate. It is better to obtain the kinetic parameter by separating of the data sets at each molar ratio.

\section{Conclusion}

The kinetic model adequately captures the main feature experimental work. The approach of kinetic modeling proved fruitful, indicates that all important reactions are observed. Seven reaction terms represent the reactions that occurred in the nitration of glycerol. The position of hydroxyl group in molecule causes difference reaction rates. The primary hydroxyl group is more reactive than secondary hydroxyl group. The parameter values describe that the $1^{\text {st }}, 3^{\text {rd }}, 5^{\text {th }}$ and $7^{\text {th }}$ reaction rates are very fast. On the contrary, the the $2^{\text {nd }}, 4^{\text {th }}$ and $6^{\text {th }}$ reaction rates are slow. All reactions represent reactions for the nitration.

\section{Acknowledgements}

The authors thankfully acknowledge the Erasmus Mundus Programme EuroAsia which has awarded scholarships to the author. The authors also convey our sincere gratitude to Chemical Engineering Division, Chemical and Biological Department, Chalmers University of Technology, Sweden for providing equipments and chemicals for this research.

\section{Nomenclature}

$$
\begin{array}{ll}
\mathrm{A} & =\text { pre-exponential factor, } \mathrm{m}^{3} /(\mathrm{mol})(\mathrm{s}) \\
\mathrm{C}_{\mathrm{i}} & =\text { concentration of compound } \mathrm{i}, \mathrm{mol} / \mathrm{L} \\
\mathrm{E}_{\mathrm{A}} & =\text { activation energy, } \mathrm{kJ} / \mathrm{mol} \\
\mathrm{K}_{\mathrm{i}} & =\text { equilibrium constant at reaction } \mathrm{i} \\
\mathrm{k}_{\mathrm{i}} & =\text { rate constants of reaction } \mathrm{i}, \mathrm{m}^{3} /(\mathrm{mol})(\mathrm{s}) \\
\mathrm{k}_{\mathrm{ref}, \mathrm{i}} & =\text { rate constants of reaction i at average temperature, } \mathrm{m}^{3} /(\mathrm{mol})(\mathrm{s}) \\
\mathrm{PGN} & =\text { polyglycidyl nitrat } \\
\mathrm{R} & =\text { gas consntants } \\
\mathrm{TNG} & =\text { nitroglycerin } \\
\mathrm{T} & =\text { reaction temperature, } \mathrm{K} \\
\mathrm{T}_{\text {ref }} & =\text { average temperature, } \mathrm{K} \\
\Delta \mathrm{H}^{\mathrm{i}} & =\text { heat of reaction, } \mathrm{kJ} / \mathrm{mol} \\
1,2-\mathrm{DNG} & =1,2 \text {-dinitroglycerin } \\
1,3-\mathrm{DNG} & =1,3 \text {-dinitroglycerin } \\
1-\mathrm{MNG} & =1 \text {-mononitroglycerin } \\
2-\mathrm{MNG} & =2 \text {-mononitroglycerin }
\end{array}
$$

\section{References}

Astuti, E., Supranto, R., \& Prasetya, A. (2014). Determination of The Temperature Effect on Glycerol Nitration Processes Using The HYSYS Predictions and The Laboratory Experiments. Indonesian Journal of Chemistry, 14(1).

Ayoub, M., \& Abdullah, A. Z. (2012). Critical Review on the Current Scenario and Significance of Crude glycerol resulting from biodiesel industry towards more sustainable renewable energy industry. Renewable and Sustainable Energy Reviews, 16, 2671-2686. http://dx.doi.org/10.1016/j.rser.2012.01.054

Braithwaite, P. C., Lund, G. K. \& Wardle, R. B. (1996). High Perfomance Pressable Explosive Compositions. US Patent, 5, 587-553.

Coombes, R. G., Moodie, R. B., \& Schofield, K. (1968). Electrophilic aromatic substitution. Part I. The nitration of some reactive aromatic compounds in concentrated sulphuric and perchloric acids. J. Chem. Sot. B, 800-804. 
Highsmith, T. K., \& Johnston, H. E. (2005). Continuous Process and System for Production of glycidyl nitrate from glycerin, nitric acid and caustic and conversion of glycidyl nitrate to poly (glycidyl nitrate). US Patent No. 6, 870061 .

Highsmith, T. K., Sanderson, A. J., Cannizzo, L. F., \& Hajik, R. M. (2002). Polymerization of Poly(glycidyl Nitrate) from High Purity Glycidyl Nitrate Synthesized from Glycerol. US Patent No. 6, 362, 311.

Kazakov, A. I., Lagodzinskaya, G. V., Andrienku, L. P., Yunda, N. G., Korolev, A. M., Rubtsov, Y. I., ... Eremenko, L. T. (1990a). Study of nitration equilibrium in the glycerin-aqueous nitric acid system.1. dependence of the equilibrium constants of nitration reactions on the temperature, acidity of the medium, and structure of the nitrated compound. Russian Chemical Bulletin, 39(8), 1560-1565. http://dx.doi.org/10.1007/BF00961477

Kazakov, A. I., Kirpichev, E. P., Lagodzinskaya, G. V., Andrienku, L. P., Yunda, N. G., Korolev, A. M., Rubtsov, Y. I., ... Eremenko, L. T. (1990b). Study of nitration equilibrium in the glycerin-aqueous nitric acid system. 2. Change in $\Delta \mathrm{H}$ and $\Delta \mathrm{S}$ in the nitration reactions. Russian Chemical Bulletin, 39(8), 1565-1570. http://dx.doi.org/10.1007/BF00961478

Kiss, A. A., \& Ignat, R. M. (2012). Enhanced methanol recovery and glycerol separation in biodiesel production - DWC makes it happen. Applied Energy, 99, 146-153. http://dx.doi.org/10.1016/j.apenergy.2012.04.019

Lu, K. T., Luo, K. M., Yeh, T. F., \& Lin, P. C. (2008). The Kinetic Parameters and Safe Operating Conditions of Nitroglycerine Manufacture in The CSTR of Biazzi Process. Process Saf. Environ. Prot., 86(1), 37-47. http://dx.doi.org/10.1016/j.psep.2007.10.006

Moodie, R. B., Schofield, K., \& Tobin, G. D. (1977). Electrophilic Aromatic Substitution. Part 17. Products, Kinetics, and Mechanism of Nitration in Trifluoroacetic Acid. J. Chem. Soc. Perkin Trans., 2, 1688-1693. http://dx.doi.org/10.1039/p29770001688

Moodie, R. B., Schofield, K., \& Tobin, G. D. (1978). Electrophilic Aromatic Substitution. Part 19. The Nitration of Some Aromatic Compounds in Perchloric Acid. J. Chem. Soc. Perkin Trans., 2, 318-323. http://dx.doi.org/10.1039/p29780000318

Provatas, A. (2000). Energetic Polymers and Plasticisers for Explosive Formulations. A Review of Recent Advances. DSTO Aeronautical and Maritime Research Laboratory, Melbourne.

Rubtsov, Y. L., \& Kazakov, A. I. (1997). Equilibrium constants of nitration of alcohols and thermal stability of their nitrates. Russian Chemical Bulletin, 46(10), 1707-1709. http://dx.doi.org/10.1007/BF02495120

Sanderson, A. J.., \& Martins, L. J. (2004). Process for Making Stable cured poly (glycidyl nitrate). US Patent No. $6,730,181$.

Sanderson, A. J., Martins, L. J., \& Dewey, M. A. (2005). Process for Making Stable cured poly(glycidyl nitrate) and energetic compositions comprising same. US Patent No. 6, 861, 501.

Van Woezik, B. A. A., \& Westerterp, K. R. (2000). The Nitric Acid Oxidation of 2-octanol. A model reaction for multiple heterogeneous liquid-liquid reactions. Chemical Engineering and Processing, 39(6), 521-537. http://dx.doi.org/10.1016/S0255-2701(00)00099-4.

Willer, R. L., \& McGrath, D. K. (1997). Clean Space Motor/Gas Generator Solid Propellants. US paten No. 5 , 591, 936.

Willer, R. L., Stern, A. G., \& Day, R. S. (1995). Polyglycidyl nitrate Plasticizer. US Patent No. 5, 380, 777.

Yunda, N. G., Lagodzinskaya, G. V., Kazakov, A. I., Korolev, A. M., Rubtsov, Y., Manelis, G. B., \& Eremenko, L. T. (1991). Nitration equilibrium in the glycerol-aqueous-nitric-acid system 3. PMR parameters, conformational structure, and main properties of glycerol and its nitrates. Russian Chemical Bulletin, 40(2), 325-332. http://dx.doi.org/10.1007/BF00965425

\section{Copyrights}

Copyright for this article is retained by the author(s), with first publication rights granted to the journal.

This is an open-access article distributed under the terms and conditions of the Creative Commons Attribution license (http://creativecommons.org/licenses/by/3.0/). 